\title{
OVO CONSTRUCTO DE GERENCIAMENTO DA EXPERIÊNCIA AMPLIADA DO CLIENTE: INTEGRAÇÃO DOS AMBIENTES OFF-LINE E ON-LINE
}

\author{
Recebido: 08/10/2020 \\ Aprovado: 09/03/2021
}

\author{
1 João Luiz Gilberto de Carvalho \\ ${ }^{2}$ Geraldo Luciano Toledo
}

\section{Resumo}

Objetivo: Analisar como as dimensões da integração dos ambientes off-line e on-line estão presentes no gerenciamento das experiências, no segmento de varejo supermercadista

Método: Análise de conteúdo e categorização do estado da arte do gerenciamento da experiência do cliente (GEC), conforme elementos do modelo de Schmitt (2004) ambientes experienciais; plataformas de experiências; experiências desejadas para a marca; interfaces de interação com o cliente, e; inovação contínua.

Originalidade/Relevância: $O$ estudo e suas dimensões amplia o conceito de relacionamento com o cliente, levando a uma visão que abrange a criação de valores. Preenche lacunas sobre GEC ao apresentar ferramentais gerenciais para o fenômeno da experiência.

Resultados: São apresentadas interações das dimensões do GEC que embasam o novo constructo nomeado de 'experiência ampliada do cliente no supermercado', que implementa o modelo de Terblanche (2018), agregando uma nova dimensão: a integração das operações off-line e on-line. Esta, diz respeito ao acesso dos clientes no canal físico do supermercado, integrando recursos, tecnologias e características do ambiente digital, com operações sob a concepção omnichannel.

Contribuições teóricas / metodológicas: Arcabouço teórico e constructo que amplia o escopo do GEC uma vez que evidencia a necessidade de integração dos ambientes físico e virtual para melhorar as sensações experienciais. O estudo se configura como teoria para gerenciamento dos estímulos que afetam os clientes, as operações dos processos no varejo e as atmosferas das lojas.

Contribuições sociais / para a gestão: Os resultados contribuem para que gestores varejistas melhorem as experiências do cliente no ponto de venda, obtendo vantagem competitiva.

Palavras-chave: Gerenciamento da experiência do cliente. Varejo. Varejo experiencial. Supermercado. Omnichannel.

\section{Como Citar:}

Carvalho, J., \& Toledo, G. (2021). Novo Constructo de Gerenciamento da Experiência Ampliada do Cliente: Integração dos Ambientes Off-Line e On-Line. Future Studies Research Journal: Trends and Strategies [FSRJ], 13(2), 203-229. doi: https://doi.org/10.24023/FutureJournal/2175-5825/2021.v13i2.474

${ }^{1}$ Universidade Estadual de Londrina - UEL, Paraná, (Brasil). E-mail: jlcarvalho@alumni.usp.br Orcid id: https://orcid.org/0000-0002-7908-3712

${ }^{2}$ Universidade de São Paulo - USP, São Paulo, (Brasil). E-mail: gltoledo@usp.br Orcid id: https://orcid.org/0000-0002-5781-0114 


\title{
NEW CONSTRUCT OF MANAGING THE EXPANDED EXPERIENCE OF THE CUSTOMER: INTEGRATION OF THE OFF-LINE AND ONLINE ENVIRONMENTS
}

\begin{abstract}
Purpose: To analyze how the integration dimensions of offline and online environments are present in the management of experiences, in the supermarket retail segment

Method: The method focuses on analysis and categorization of the state of the art of customer experience management (CEM), according to elements of Schmitt's model (2004) - experiential environments; experience platforms; desired experiences for the brand; customer interaction interfaces; continuous innovation.
\end{abstract}

Originality / Relevance: This study and its dimensions expands the concept of relationship with the customer, leading to a vision that encompasses the creation of value. It fills gaps of CEM by presenting managerial tools for the phenomenon of experience.

Findings: Interactions of the CEM dimensions are presented that support the new construct named 'expanded customer experience in the supermarket', which implements the Terblanche model (2018), adding a new dimension: the integration of offline and online operations. This concerns the access of customers to the physical channel of the supermarket, integrating resources, technologies and characteristics of the digital environment, with operations under the omnichannel concept.

Theoretical / methodological contributions: Theoretical framework and new construct that expands the scope of the CEM since it highlights the need to integrate the physical and virtual environments to improve experiential sensations. The study is configured as a theory for managing the stimuli that affect customers, the operations of processes in retail and the atmospheres of stores.

Social / management contributions: The results help retail managers to improve customer experiences at the point of sale, getting a competitive advantage.

Keywords: Customer experience management. Retail. Experiential retail. Supermarket and Grocery. Omnichannel. 


\section{INTRODUÇÃO}

Proporcionar experiências positivas de consumo é um dos atuais desafios da gestão de marketing, seja em nível estratégico ou operacional, proporcionando diferenciais de mercado perante os concorrentes (Terblanche, 2018). Apesar de a literatura em Marketing apresentar teorias seminais sobre as experiências do consumidor a partir da década de 1960 (Lemon \& Verhoef, 2016), o assunto ganha mais relevância quando as of ertas têm muitas semelhanças e as empresas apresentam propostas de valores parecidas, uma vez que as experiências vivenciadas pelos consumidores influenciam o relacionamento duradouro entre empresas e consumidores, assim como as suas relações de trocas, ainda que tenham alta subjetividade (Homburg, Jozić, \& Kuehnl, 2017; Höpner, Ganzer, Chais, \& Olea, 2015).

A jornada de compra consiste em todo o percurso realizado pelo consumidor durante o processo de compra, do reconhecimento das necessidades, passando pela busca de alternativas para atender a essas necessidades, a tomada de decisão em si e os momentos que envolvem o pós-compras (Puccinelli et al., 2009). Pode-se afirmar que a jornada de compra está cada vez mais complexa devido ao aumento de ofertas de produtos e marcas, assim como a operação dos diversos canais de contato com o consumidor (Kannan \& Li, 2017). Dessa forma, mudou também a maneira de decidir as compras e, consequentemente, o nível de exigência por parte do consumidor.

Até então, a literatura sobre canais de distribuição apresentou pouco progresso na explicação de como as empresas podem gerenciar a experiência do consumidor em toda jornada de compras (Lemon \& Verhoef, 2016). Embora a integração de canais seja considerada importante para a retenção dos clientes (Neslin \& Shankar, 2009) e reconhecida como vantajosa e promissora para os varejistas, seus ef eitos sobre as reações dos clientes ainda não estão claros (Herhausen, Binder, Schoegel, \& Herrmann, 2015). Dessa forma, ainda é um desafio para a pesquisa em gerenciamento de experiências a determinação deste constructo (GEC - gerenciamento de experiências do cliente) por meio dos múltiplos pontos de contato em diferentes estágios da jornada de compras (Lemon \& Verhoef, 2016).

A literatura aponta, como uma das direções estratégicas para a fundamentação de um marco teórico do gerenciamento da experiência do cliente (GEC), o estudo da conectividade dos pontos de contato, por meio da análise da integração funcional entre os ambientes on-line e off-line, possibilitando operações, funcionalidades e transições contínuas entre um e outro (Homburg et al., 2017, p. 388).

Justifica-se o estudo do gerenciamento de experiências pois este tem ampliado o conceito de relacionamento com o cliente e sua satisfação, levando a uma visão mais rica, mas ainda é limitado na literatura de Marketing, focando principalmente em métricas para 
identificar o valor do cliente, em vez da criação de valor para o cliente (Lemon \& Verhoef, 2016). Há necessidade crítica de que os pesquisadores desenvolvam um modelo conceitual da experiência integrada do cliente na jornada de compras, identificando vínculos para pesquisas futuras (Lemon \& Verhoef, 2016). Além disso, uma das lacunas de estudos sobre - GEC é identificar percepções, sob a perspectiva das empresas varejistas, mais aprofundadas sobre o fenômeno da experiência do consumidor, incluindo características culturais, capacidades dinâmicas e orientações estratégicas (Homburg et al., 2017). Entender as experiências que integram os ambientes virtuais e físicos, assim como compreender as diferentes formas de participação do varejista na experiência, são desafios relevantes aos pesquisadores (Antéblian, Filser, \& Roederer, 2013).

Assim, é preciso contextualizar a integração dos ambientes físico e virtual em um determinado segmento de mercado consumidor. O setor supermercadista reúne as condições, características e relevância necessárias para o presente ensaio, devido sua importância econômica e influência no cotidiano das pessoas. Em 2018, o segmento supermercadista faturou aproximadamente $R \$ 360$ bilhões (ABRAS - Associação Brasileira de Supermercados, 2019) e uma de suas características é ser um setor bastante fragmentado. Grandes empresas nacionais e internacionais fazem parte do segmento, que também tem participações importantes de microempresas, regionais, muitas com apenas uma loja. São empresas que participam dos hábitos dos consumidores, de seu dia a dia e desempenham um papel integrador entre indústrias e usuários finais de inúmeros produtos diferentes. No Brasil, as cinco maiores empresas do setor detêm cerca de $45 \%$ do faturamento nacional. O segmento dos supermercados apresenta um alto volume de produtos comercializados, mas com baixas margens de operação. É estimado que são mais de 11 mil pontos de venda, empregando quase 710 mil pessoas diretamente (SBVC Sociedade Brasileira de Varejo e Consumo, 2018).

Tendo por referência o contexto e o cenário expostos, optou-se por direcionar a pesquisa para o seguinte objeto de estudo: gerenciamento da experiência do cliente no varejo, com foco específico no varejo supermercadista. Observa-se que a literatura de marketing já apresenta estudos a respeito de alguns dos constructos que compõem esse tema, como gerenciamento da experiência, integração de canais, processos de compras utilitárias e o comportamento do consumidor em ambientes físicos e virtuais integrados nas operações de varejo. Entretanto, ainda persistem lacunas para estudos futuros. Por outro lado, é importante analisar as experiências sob a ótica do varejo como suporte para enriquecer a discussão teórica a respeito de um importante segmento da economia e que apresenta relevância no cotidiano dos consumidores.

À luz do exposto, propõe-se a seguinte questão de pesquisa: como as dimensões da integração dos ambientes off-line e on-line estão presentes no gerenciamento da experiência do cliente, no varejo supermercadista? Dessa forma, o objetivo do ensaio é 
analisar como as dimensões da integração dos ambientes off -line e on-line estão presentes no gerenciamento da experiência do cliente, no segmento de varejo supermercadista.

\section{REVISÃO BIBLIOGRÁFICA}

\subsection{GERENCIAMENTO DA EXPERIÊNCIA DO CLIENTE}

Estudos a partir da década de 1950 evidenciam que as compras estão ligadas às aspirações, desejos e impulsos humanos. Os consumidores desejam bens e serviços porque seus benefícios e características proporcionam experiências agradáveis (Abbott, 1955; Lemon \& Verhoef, 2016). "O que as pessoas realmente desejam não são produtos, mas experiências satisfatórias" (Abbott, 1955, p. 39).

As experiências vivenciadas nos momentos e nos processos de consumo passaram a merecer muito mais atenção na literatura de marketing a partir da publicação dos estudos seminais de Holbrook e Hirschman (1982). Os autores apresentaram a visão experiencial, com diversos aspectos subjetivos e particulares aos consumidores, a qual considera a experiência de consumo como um fenômeno que busca envolver "um fluxo constante de fantasias, sentimentos e diversão" (Holbrook \& Hirschman, 1982, p. 132). Essa perspectiva experiencial considera o consumo como um estado repleto de significados simbólicos, buscas hedônicas e aspectos estéticos. Quando o consumidor compra uma determinada experiência, ele paga para desfrutar uma série de eventos memoráveis, que devem envolvê-lo de maneira absolutamente pessoal (B. J. I. Pine \& Gilmore, 2011).

Dessa forma, a experiência do cliente é um constructo multidimensional que tem foco em suas respostas cognitivas, emocionais, comportamentais, sensoriais e sociais em relação às ofertas de uma empresa durante todo o processo de compra (Lemon \& Verhoef, 2016). As experiências dos clientes envolvem um processo de interações entre uma pessoa, um objeto que será consumido e uma determinada situação, o qual gera percepções, reações e significados para a pessoa em questão (Antéblian, Filser, \& Roederer, 2013).

As experiências devem envolver prazer, fantasias e emoções nos processos de compras, assim como outras dimensões importantes dos consumidores: suas experiências passadas, atenção, imaginação, memória e afetividade (Hernández-Ortega \& Franco, 2018; Holbrook \& Hirschman, 1982; Höpner et al., 2015). As experiências são fatores importantes para a decisão do consumidor durante o processo de compras: nas etapas de busca de informações, na avaliação das alternativas (Schmitt, 2004), na fase da interação na loja (Otieno, Harrow, \& Lea-Greenwood, 2005) ou no pós-compra (Puccinelli et al., 2009). Assim, é apresentado o conceito de jornada do consumidor, ou jornada de compras. Essa jornada é o caminho ao longo do tempo, quando o consumidor se relaciona com as 
empresas durante os vários estágios do ciclo de compras e em diversos pontos de contato (Lemon \& Verhoef, 2016; Micheaux \& Bosio, 2018). O termo jornada do consumidor também é geralmente usado em referência a um processo ou sequência de atividades por meio do qual o cliente acessa ou usa um produto (Følstad \& Kvale, 2018).

A perspectiva da jornada do cliente auxilia entender como acontecem as experiências dos clientes, possibilitando informações e conhecimento para melhoria e gerenciamento delas (Følstad \& Kvale, 2018). Os autores consideram a jornada do consumidor como algo que pode ser planejado e que deve incluir a experiência percebida pelo cliente quando está em contato com os serviços of erecidos pelas empresas. Entretanto, as jornadas dos clientes devem ser entendidas como mais do que apenas a série de etapas (ou pontos de contato) pelas quais um cliente passa. Respostas emocionais e cognitivas do cliente também influenciam e são influenciadas pela própria jornada.

Pine e Gilmore (2011) explicam que a natureza do valor econômico, na crescente competitividade, evolui da mercadoria sem valores agregados para os bens manufaturados, depois para as prestações de serviços e finalmente para as experiências. Bens e serviços não são mais suficientes para gerar diferenciais valorizados pelos consumidores em geral. As experiências surgem para a criação de um novo patamar de valores aos clientes.

\subsubsection{Experiências nos Ambientes Varejistas}

A criação de uma experiência superior aos clientes pode gerar vantagens competitivas ao varejo (Grewal, Roggeveen, \& Nordfält, 2017) uma vez que o conceito de experiência do cliente apresenta características holísticas (Verhoef et al., 2009). Os autores afirmam que a experiência também é criada por elementos que o varejista pode controlar, como a interface do serviço, o ambiente do varejo, sortimento de produtos e preço. Ainda assim, a experiência do cliente "envolve as respostas cognitivas, afetivas, emocionais, sociais e físicas" por parte do cliente ao varejista (Verhoef et al., 2009, p. 32).

No modelo conceitual apresentado por Verhoef et al. (2009), conforme demonstrado na Figura 1, as estratégias para o gerenciamento das experiências dos clientes têm características antecedentes e moderadoras, necessárias à construção desse tipo de relacionamento. Nesse sentido, a experiência do cliente envolve a totalidade da jornada de consumo - fases da pesquisa, da compra, do consumo e do pós-consumo - e engloba os vários canais de varejo disponíveis. 


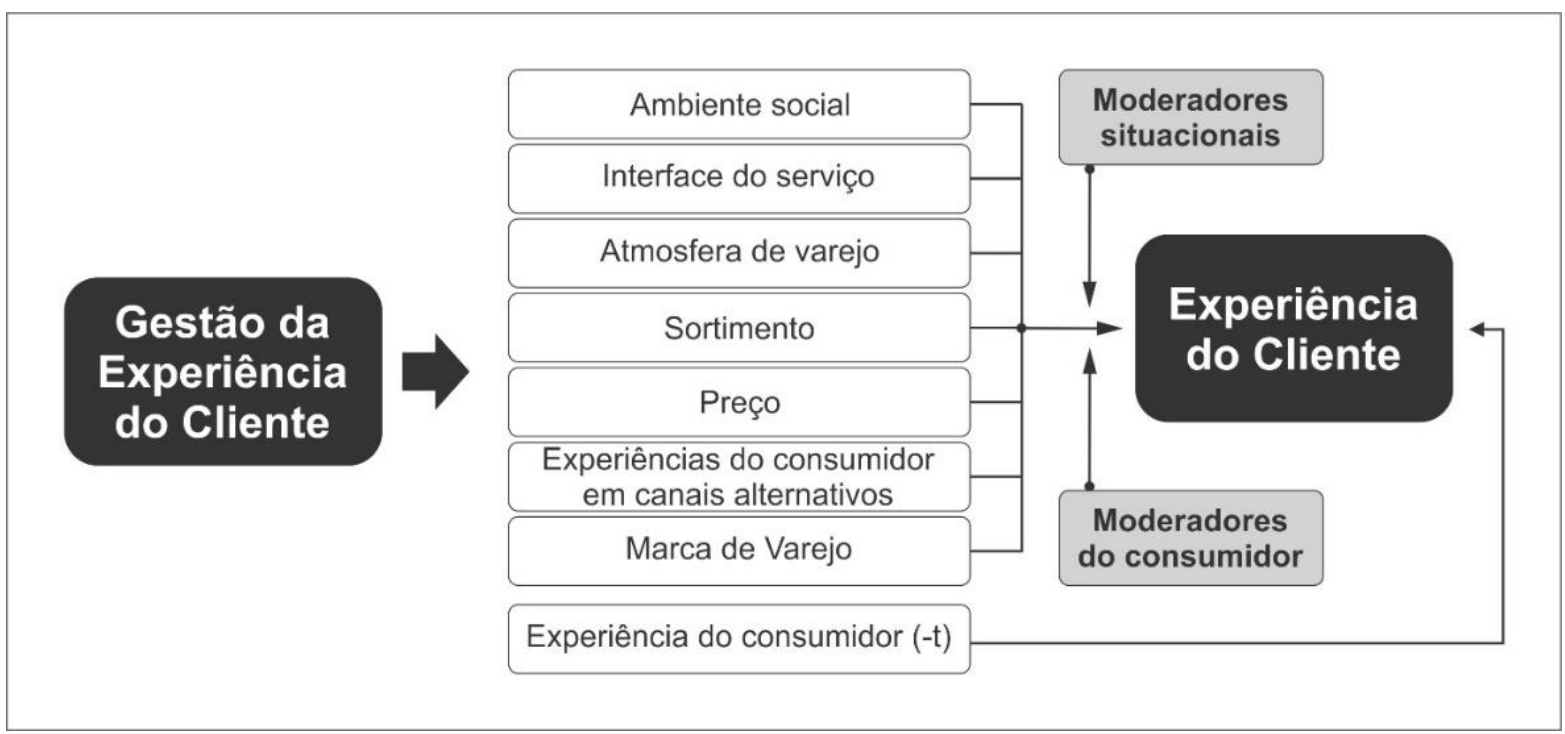

Figura 1: Modelo conceitual de criação de experiência de cliente

Fonte: Verhoef et al. (2009, p. 32).

O gerenciamento da experiência do cliente (GEC) consiste em deixar as interações com os clientes mais amigáveis, fáceis e convenientes (B. J. I. Pine \& Gilmore, 2011) e é caracterizado como uma estratégia para administrar os pontos de contato em que o cliente interage com a empresa e com os produtos (bens ou serviços), que influenciam dessa forma a experiência percebida pelo cliente (Grewal, Levy, \& Kumar, 2009). Segundo Schmitt (2004, p. 26), o gerenciamento da experiência do cliente é "o processo de gerenciar, estrategicamente, toda a experiência de um cliente com determinado produto ou empresa". Assim, cresce a necessidade da gestão das experiências por parte das organizações (Lemon \& Verhoef, 2016), otimizando seus recursos de infraestrutura, humanos (Terblanche, 2018), financeiros e logísticos, a fim de proporcionar os melhores momentos possíveis quando dos pontos de contato e alinhados às demandas dos clientes (Höpner et al., 2015).

O GEC trata da ideia de satisfação orientada por processos voltados para a construção de relações entre as empresas e os clientes nos pontos de contato de maneira que sejam mutuamente positivas (Schmitt, 2004). Nesse sentido, ponto de contato é definido como o momento de contato direto ou indireto do cliente com a marca ou empresa, podendo ser positivo ou negativo (Baxendale, Macdonald, \& Wilson, 2015; Zomerdijk \& Voss, 2010), verbal ou não verbal (Ieva \& Ziliani, 2018a), podem acontecer nos ambientes on-line e offline (Ieva \& Ziliani, 2018b) e também acontecem por meio dos diversos canais de distribuição existentes por onde os clientes interagem com as empresas (Neslin et al., 2006).

Cada vez mais esse processo é conduzido por novas tecnologias e isso exige das empresas mudanças e adaptações rápidas para ajustar as operações aos novos desejos 
dos consumidores e às mudanças do mercado (Koetz, 2018). Ainda considerando a perspectiva da empresa que busca gerenciar as experiências, o valor gerado a partir do conjunto de interações entre o cliente e a organização demonstra ter impacto potencial nas medidas tradicionais de desempenho - participação no mercado, vendas e lucratividade, por exemplo - e nos ativos intangíveis da empresa - valor de marca e posicionamento (Gentile, Spiller, \& Noci, 2007).

O modelo proposto por Schmitt (2004) estrutura um projeto para gerenciamento das experiências dos clientes com etapas que abrangem a análise ambiental, o preparo da estratégia e a sua ef etiva implementação. O Quadro 1 apresenta as etapas e suas principais características.

\begin{tabular}{|c|l|l|}
\hline \multicolumn{2}{|c|}{ Etapas } & \multicolumn{1}{c|}{ Características } \\
\hline $\mathbf{1}^{\text {a }}$ & $\begin{array}{l}\text { Análise do ambiente } \\
\text { experiencial do cliente }\end{array}$ & $\begin{array}{l}\text { Contexto sociocultural dos clientes, suas necessidades, estilos de vida e } \\
\text { aspirações experienciais. }\end{array}$ \\
\hline $\mathbf{2}^{\mathbf{a}}$ & $\begin{array}{l}\text { Construção de plataforma } \\
\text { de experiências e pontos de } \\
\text { contato }\end{array}$ & $\begin{array}{l}\text { A promessa de valor experiencial especifica com exatidão aquilo que o } \\
\text { posicionamento apresentará ao cliente, ou seja, estabelece quais as } \\
\text { vantagens que o cliente terá com determinada experiência. }\end{array}$ \\
\hline $\mathbf{3}^{\text {a }}$ & $\begin{array}{l}\text { Projeto da experiência } \\
\text { desejada para a marca }\end{array}$ & $\begin{array}{l}\text { Inclui aqui os elementos estáticos que o cliente encontra durante a } \\
\text { jornada - aspectos da identidade visual da marca, ferramentas de } \\
\text { comunicação integrada,embalagem, entre outros. }\end{array}$ \\
\hline $\mathbf{4}^{\mathbf{a}}$ & $\begin{array}{l}\text { Estruturação da interface } \\
\text { de interação com o cliente }\end{array}$ & $\begin{array}{l}\text { Abrange os pontos de contato e interface dinâmicos que a empresa pode } \\
\text { desenvolver com o cliente. Isso acontece pessoalmente, no a mbiente } \\
\text { virtual, por telefone, enfim, a interface vai muito além de um software } \\
\text { de gestão de relacionamento com o cliente. Trata também do design na } \\
\text { interface - flexibilidade, estilo, conteúdo e tempo de duração do ponto } \\
\text { de contato. }\end{array}$ \\
\hline $\mathbf{5}^{\text {a }}$ & $\begin{array}{l}\text { Compromisso com a } \\
\text { inovação contínua }\end{array}$ & $\begin{array}{l}\text { Deve estar intimamente ligado às inovações propostas pela empresa e } \\
\text { esse não é um processo estático, deve ser dinâmico e continuado. As } \\
\text { inovações podem criar novas e relevantes experiências aos clientes, } \\
\text { melhorando-as. }\end{array}$ \\
\hline
\end{tabular}

Quadro 1: Características das etapas de Projeto de Gerenciamento de Experiências

Fonte: Adaptado de Schmitt (2004).

Considerando o contexto do presente estudo - varejo de supermercado - Terblanche (2018) identificou que estímulos no ambiente supermercadista têm influência positiva e significativa nas satisfações e nas experiências dos clientes. Nesse contexto, a pesquisa proporcionou embasamento para formulação do constructo da experiência de compra especificamente no ambiente do supermercado que abrange cinco fatores, conforme demonstrado na Figura 2. 


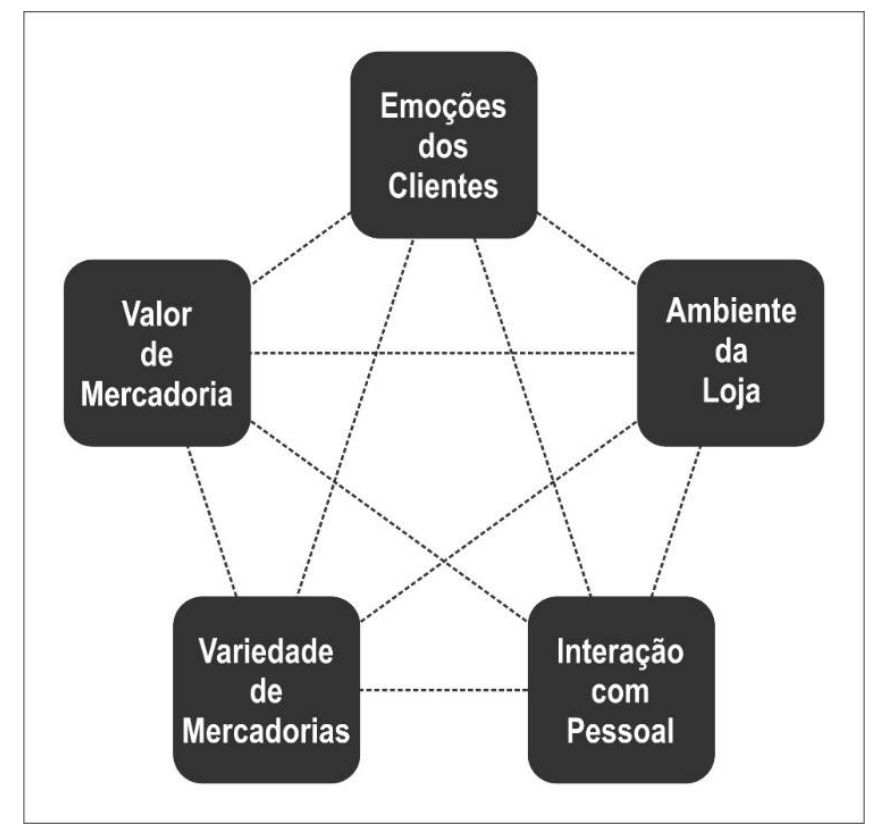

Figura 2: Constructo da experiência do cliente no supermercado Fonte: Adaptado de Terblanche (2018).

O primeiro item do constructo - valor de mercadoria - é resultado do preço do produto percebido pelo cliente, da qualidade desse produto e no custo-benefício percebido pelo cliente na sua intenção por comprar em determinado varejista. Assim, esse fator sugere uma relação entre os esforços do cliente quanto ao pagamento financeiro e os benefícios oferecidos pelo supermercado (Baker, Parasuraman, Grewal, \& Voss, 2002; Sirohi, McLaughlin, \& Wittink, 1998; Terblanche, 2018).

O segundo item do constructo - ambiente da loja - abrange os diversos estímulos do ambiente do supermercado, sua decoração, instalações físicas, check-outs, mobiliário para exposição dos produtos, leiaute, expositores, displays, enfim, todos os itens que influenciam as percepções dos clientes no supermercado (Mohan, Sivakumaran, \& Sharma, 2013; Terblanche, 2018). Nesse fator do constructo também está inclusa a qualidade cinética do ambiente da loja - a movimentação e o gestual dos clientes durante as compras (Bonnin \& Goudey, 2012).

O terceiro item do constructo - interação com pessoal de atendimento - é a representação de que essa interação afeta a experiência do cliente em uma loja supermercadista. A satisfação dos clientes é frequentemente associada ao tipo de atendimento recebido e os pontos de contato que acontecem nessa interação. Simpatia e perícia dos atendentes influenciam diretamente na satisfação e no desejo de comprar novamente em determinada loja (Puccinelli et al., 2009; Terblanche, 2018).

O quarto item do constructo - variedade de mercadorias - se caracteriza como um desafio para o varejista do supermercado porque o sortimento of erecido deve estar em 
sintonia e equilíbrio com as expectativas dos clientes. Assim, foi verificado que as atitudes dos clientes em relação à sua probabilidade de realizar comprar em determinada loja está positivamente relacionada à variedade disponível dos produtos (Terblanche, 2018).

O quinto item do constructo - emoções dos clientes na loja - abrange os aspectos emocionais do próprio cliente, invocados no ambiente físico, uma vez que a atmosfera da loja afeta tantos os aspectos cognitivos quanto emocionais dos clientes. As emoções têm importância no contexto de uma experiência agradável no supermercado, sendo essencial que as empresas avaliem continuamente até que ponto elas são provocadas e atendidas durante a jornada de compras (Babin, Darden, \& Griffin, 1994; Terblanche, 2018) .

Dessa forma, considerando os fatores apontados no constructo, a satisfação cumulativa do cliente inclui suas experiências durante as diversas visitas a um determinado supermercado e refere-se a uma avaliação holística das experiências totais de compra nesse varejista ao longo do tempo (Terblanche, 2018).

\subsection{ATMOSFERA DE VAREJO}

Existem diversos ativos intangíveis que desempenham papel crítico no sucesso ou fracasso de uma loja (Martineau, 1958). Alguns desses fatores intangíveis podem ser explicados por meio da criação de um ambiente em que os clientes tenham sensações positivas, com corredores amplos e limpos, onde "fazer compras . . é uma experiência agradável em vez de uma obrigação rotineira" (Martineau, 1958, p. 47). É reconhecida a importância do ambiente varejista como ferramenta de diferenciação de mercado e satisfação do cliente (Baker, Levy, \& Grewal, 1992; Levy \& Weitz, 2012; Vieira, 2013). O conceito de atmosfera de loja foi criado por Kotler (1973) e apresentado em um artigo clássico da área mercadológica (Baker et al., 1992; Hoffman \& Turley, 2002; Milliman \& Fugate, 1993; Poncin \& Ben Mimoun, 2014).

O termo atmosfera descreve um projeto de ambiente com elementos sensoriais, que busca criar determinados efeitos positivos nos consumidores (Kotler, 1973). Esse conjunto de elementos que forma a atmosfera são considerados estímulos, que têm o objetivo de causar respostas comportamentais por parte dos clientes, como a efetivação da compra (Kumar \& Karande, 2000; Turley \& Milliman, 2000). "Mais especificamente, a atmosfera é o conjunto de esforços para criar ambientes de compras que produzam efeitos emocionais específicos no comprador e que aumentem sua probabilidade de compra" (Kotler, 1973, p. 50). O conceito pode ser implementado, sendo "atmosfera: a coleção de estímulos (variáveis atmosféricas) que incidem sobre os sentidos de um indivíduo, afetando a experiência total de estar em um determinado lugar em um determinado momento" (Milliman \& Fugate, 1993, p. 68). 
Diversos estudos foram realizados sobre a relação entre atmosfera de lojas, percepções a respeito delas e as reações emocionais dos clientes, tendo os aspectos sensoriais como foco: visão (Bitner, 1992; Bonnin \& Goudey, 2012; Lam, 2001), olfato (Aguiar \& Farias, 2014; Brito, Vieira, \& Espartel, 2011; Errajaa, Legohérel, \& Daucé, 2018), audição (Baker et al., 2002; Hoffman \& Turley, 2002; Turley \& Milliman, 2000), tato (Balasubramanian, Raghunathan, \& Mahajan, 2005; Cook, 2014; Flavián, Gurrea, \& Orús, 2016; Helm, Kim, \& Van Riper, 2018) e paladar (D'Ippolito \& Timpano, 2016; Kim et al., 2018; Levy \& Weitz, 2012; Spence et al., 2014).

O varejo supermercadista abrange um tipo essencial e rotineiro de compras e de comportamentos específicos dos clientes. A experiência de compra em supermercados é caracterizada por muitos estímulos da loja (como disposição dos produtos, marcas, iluminação e diversas informações) e pela repetição da compra em intervalos regulares de tempo (uma ou mais vezes por semana, por exemplo). Essas características criam um contexto em que as intenções dos clientes e os resultados dependem de diversos fatores situacionais (Park, Iyer, \& Smith, 1989). Pesquisas demonstram que, apesar de supermercados serem considerados, em geral, como locais de compras utilitárias, caso of ereçam opções de entretenimento, ou atividades não rotineiras (por exemplo, cursos de culinária), os clientes são atraídos para o ambiente da loja e percebem as experiências positivas (Kim, Ham, Moon, Chua, \& Han, 2018; Pine \& Gilmore, 2011).

Além da força influenciadora dos ambientes de compras e do aumento dos canais de distribuição, nos últimos tempos houve uma multiplicação das plataformas de compras, alterando a própria jornada de consumo, seja no estágio pré-compra, no momento efetivo da compra (momento da verdade) ou no estágio pós-compra. O consumidor pode efetuar compras por meio dos diversos pontos de contato disponíveis: loja física, loja virtual no site da própria organização, operação marketplace em outros sites (Hwangbo, Kim, \& Cha, 2017), telefones, catálogos físicos ou virtuais, quiosques de autoatendimento, plataformas em mídias sociais ou as variadas possibilidades da tecnologia móvel - apps, smartphones, buscadores, entre outros (Shankar, Venkatesh, Hofacker, \& Naik, 2010). "Cada vez mais, o sucesso no varejo é menos sobre o que [itálicos nossos] os varejistas vendem e mais sobre como [itálico nosso] eles vendem" (Sachdeva \& Goel, 2015, p. 290).

\subsection{VAREJO MULTICANAL INTEGRADO: CROSS-CHANNEL}

Varejistas multicanais são aqueles que vendem mercadorias ou serviços por meio de mais de um canal, sendo geralmente adicionados canais eletrônicos aos formatos disponibilizados pelas empresas (Levy \& Weitz, 2012). O termo multicanal é utilizado muitas vezes de forma genérica, simplesmente descrevendo a empresa que opera mais de um canal para interagir com os clientes. Pode ser considerado como um termo guarda- 
chuva que cobre outras denominações dos canais. Uma delas é o cross-channel - descrito algumas vezes em português como canal cruzado - que, além de indicar uma operação multicanal, demonstra uma efetiva integração entre os diversos canais utilizados pela empresa (Beck \& Rygl, 2015). Na operação de varejo cross-channel, existe uma integração (mesmo que parcial) entre os canais of erecidos (Beck \& Rygl, 2015; Bèzes, 2018).

A utilização de tecnologias digitais no ambiente físico do varejo gera uma transformação em atividades, processos, agentes e sortimento de produtos existentes, mas também pode introduzir novos tipos de mercadorias e prestações de serviços de forma contínua. Ilustram-se essas inovações com a operação de novos equipamentos de controle de estoque, sistemas de leitura de códigos nos produtos, sistemas de informações nas lojas e tecnologias envolvendo a interface da internet no ambiente da loja física. Enfim, inclusão de novidades que integram ambientes on-line e off-line (Hagberg, Sundstrom, \& Egels-Zandén, 2016). Também são considerados exemplos dessa integração os sistemas denominados clique-e-retire, nos quais os clientes podem comprar mercadorias no ambiente on-line e as retiram na loja física (Deloitte, 2018; Hagberg et al., 2016; Kazancoglu \& Aydin, 2018; Larke, Kilgour, \& O'Connor, 2018; Picot-Coupey, Huré, \& Piveteau, 2016) e a disponibilização de sinal wi-fi no ambiente off-line (Kang, 2018; Melero, Sese, \& Verhoef, 2016; Mosquera, Juaneda-Ayensa, Olarte-Pascual, \& SierraMurillo, 2018; Picot-Coupey et al., 2016; Rosenbaum, Otalora, \& Ramírez, 2017).

A integração de canais off-line e canais on-line é definida como o acesso ou conhecimento a respeito de um canal físico (off-line) em um canal virtual (on-line) fornecendo, por exemplo, a localização de loja física ou o sortimento disponível nessa loja em um sistema de busca virtual (Herhausen et al., 2015). A necessidade de melhorar a integração dos ambientes off-line e on-line obriga as organizações a desenvolverem suas capacidades e recursos, como infraestrutura técnica e fontes de dados. Isso fornece bases para apoiar as inovações que originarão uma experiência holística para o cliente (Bolton et al., 2018). As chamadas lojas inteligentes congregam diversos recursos digitais no ambiente físico do varejo. São definidas como aquelas lojas físicas equipadas com tecnologias que têm como objetivo criar experiências relevantes e imersivas para os clientes (Hwangbo et al., 2017), personalizando os pontos de contato (Bèzes, 2018; Homburg et al., 2017). Exemplos desse contexto são varejistas que utilizam sensores instalados dentro e fora das lojas para coletar dados, seja por identificação de imagens ou por meio das informações disponíveis nos smartphones e redes sociais. Esses dados geram informações que podem ser convertidas em sugestões aos clientes (Hwangbo et al., 2017). Cada vez mais dispositivos com inteligência artificial e robôs farão parte do varejo físico (Bolton et al., 2018; Shankar, 2018).

Além disso, outros tipos de tecnologia aprimoram a experiência dos clientes, como: realidade aumentada, dispositivos sem fio, comunicações via conexões bluetooth, sistemas 
de transmissão de dados por radiofrequência, telas sensíveis ao toque, sensores de imagens, de presença e de luz (Hwangbo et al., 2017), realidade virtual, sensores biométricos, escaneamento e imagens 3D (Pantano, 2010). Assim, ao mesmo tempo, a integração de tecnologias nos ambientes físicos das lojas auxilia na tarefa de identificar comportamentos dos clientes, proporciona momentos interativos com eles (Hwangbo et al., 2017; Pantano, 2010), passa a fazer parte da própria atmosfera da loja e influencia positivamente as percepções dos clientes (Poncin \& Ben Mimoun, 2014). Tudo isso, apesar das questões que envolvem violação de privacidade e confidencialidade das informações pessoais (Kannan \& Li, 2017; Pandey \& Chawla, 2018; Poushneh, 2018), são recursos e atividades que aumentam as conexões emocionais com o ambiente da loja (Grewal et al., 2017; Pantano \& Timmermans, 2014).

O Quadro 2 apresenta possíveis atividades que exemplificam a integração dos ambientes on-line e off-line em redes varejistas (Bendoly, Blocher, Bretthauer, Krishnan, \& Venkataramanan, 2005; Hilken et al., 2018).

\section{Atividades que proporcionam integração dos ambientais on-line e off-line}

- Anúncios comerciais e propagandas do site no ambiente da loja física.

- Anúncios comerciais e propagandas das lojas físicas no site.

- Funcionários nas lojas físicas que tenham conhecimento e sejam prestativos quanto ao uso e navegabilidade do site.

- Fornecer informações sobre a loja física (endereço, horário e estoque disponível, por exemplo) por meio do site, e-mail ou outro dispositivo eletrônico de comunicação.

- Disponibilizar estações de acesso ao site no ambiente físico da loja (via totem, quiosque ou outro dispositivo).

- $\quad$ Fornecer informações sobre sortimento e disponibilidade de produtos de cada loja física no site.

- $\quad$ Fornecer informações na loja física sobre sortimento, disponibilidade e prazos de entrega dos produtos comercializados via site.

- Aceitar trocar e devoluções de produtos nas lojas físicas para compras feitas via site.

- Permitir que os clientes comprem produtos no site e retirem na loja física.

- Utilizar aplicativos para smartphones e dispositivos de realidade aumentada em produtos e embalagens no ambiente físico da loja.

Quadro 2: Integração no ambiente varejista

Fonte: Adaptado de Bendoly et al. (2005, p. 317) e Hilken et al. (2018, p. 515).

\subsection{VAREJO OMNICHANNEL}

Para representar as inovações no cenário varejista, criou-se o termo varejo omnichannel - descrito algumas vezes em português como omnicanal - que é uma evolução dos multicanais, ampliando o foco da integração cross-channel e estimulando as transições dos clientes nos canais (Piotrowicz \& Cuthbertson, 2014; Shen, Li, Sun, \& Wang, 2018; Verhoef, Kannan, \& Inman, 2015). A palavra omni vem do latim e significa todos ou universais (Lazaris \& Vrechopoulos, 2014). 
O termo omnichannel foi utilizado pela primeira vez em um relatório sobre tendências de mercado, publicado pelo instituto de pesquisa IDC, International Data Corporation (Lazaris \& Vrechopoulos, 2014). O primeiro documento que apresentou esse termo - 2009 Top Ten Predictions for the Retail Industry - foi escrito em dezembro de 2008, apresentado e publicado em 05 de janeiro de 2009, e tratava de operações que melhoram a experiência de compras, sustentadas por inovações nos ambientes varejistas. Esse relatório não aprofundou o assunto, mas abordou o comportamento do cliente que interage com diferentes canais de maneira simultânea, com preferências para compras on-line e autoatendimento nas lojas físicas (Hand, Parker, Ortis, \& Holmes, 2009). Em uma das conversas para a elaboração desse documento, a palavra omnichannel foi pronunciada por L. Hand (comunicação pessoal, 02 de fevereiro de 2019) que, a partir de então, passou usar a referência em apresentações, reportagens, blogs e editoriais, sendo a precursora do conceito. Ainda no início de 2009, o termo foi mencionado pela executiva na maior feira mundial varejista, a NRF Retail's Big Show, que acontece em Nova Iorque.

Sob a perspectiva do varejo, omnichannel abrange o "gerenciamento sinérgico dos inúmeros canais disponíveis e dos pontos de contato do cliente, de forma a otimizar a experiência e o desempenho do cliente em todos os canais. Assim, reconhecemos que os diferentes canais interagem uns com os outros e são usados simultaneamente" (Verhoef et al., 2015, p. 176). Um dos objetivos principais do varejo omnichannel é proporcionar experiências de compras similares nos diferentes pontos de contato com os consumidores (Larke et al., 2018; Lemon \& Verhoef, 2016). Para isso devem ser evitados desequilíbrios entre comércio eletrônico e lojas físicas, como, por exemplo, políticas diferentes de preços e outras tantas distorções nas estruturas de canais. Dessa forma, os consumidores buscam as vantagens dos meios digitais, como a seleção ampla e rica de informações de produtos, dicas e opiniões de outros clientes, mas também desejam os benefícios das lojas físicas, como serviço personalizado e possibilidade de tocar os produtos, tendo uma experiência agradável (Campo \& Breugelmans, 2015; Piotrowicz \& Cuthbertson, 2014). Nesse sentido, serão utilizadas cada vez mais tecnologias no varejo com inteligência artificial, aplicadas nas análises de dados, no reconhecimento de imagens, de voz e de texto (Hwangbo et al., 2017; Shankar, 2018). No ponto central do conceito omnichannel, os termos experiência perfeita ou experiência total do cliente demonstram o grau máximo de integração entre os canais nos ambientes off-line e on-line, de maneira contínua, no relacionamento com os clientes, com consistência operacional entre os mais diversos pontos de contato, sem atritos ou pontos de fricção durante a jornada do cliente (Dziewanowska, 2015; Fulgoni, 2014; Lemon \& Verhoef, 2016; Mosquera et al., 2018; Shankar, Inman, Mantrala, Kelley, \& Rizley, 2011; Shen et al., 2018).

Uma experiência é considerada fluida quando os clientes percebem facilidades e acessibilidade nas transições entre as operações omnichannel. Assim, terão percepção 
positiva quando os esforços são reduzidos para realizar interações entre os canais, sendo incentivados a utilizar essas integrações. Isso contrasta com as operações multicanais e cross-channel, porque nelas existe a preocupação do varejista em auxiliar os clientes a concluir as transações usando os diferentes canais, sem haver uma integração total entre eles (Shen et al., 2018). A integração das operações on-line e off-line, assim como a fluidez da jornada do cliente, pode influenciar positivamente suas experiências (Antéblian et al., 2013; Bèzes, 2018; Hilken et al., 2018), tornando-as prazerosas, memoráveis e significativas (Holbrook \& Hirschman, 1982; B. J. Pine \& Gilmore, 2013; B. J. I. Pine \& Gilmore, 1998; Schmitt, 2004). Dessa forma, a concepção de gerenciamento de experiência do cliente é ampliada, agregando as múltiplas experiências que acontecem em um cenário de varejo omnichannel (Jaziri, 2019).

\section{DISCUSSÃo}

Para a realização deste ensaio, tomou-se por base diversos conceitos teóricos, sendo fundamentalmente utilizado o modelo apresentado por Schmitt (2004) na estruturação de um projeto de gerenciamento de experiências e, posteriormente, contextualizado a partir das indicações teóricas de Terblanche (2018) no setor supermercadista.

Neste estudo, a fase exploratória acontece quando da identificação do estado da arte de assuntos que compõem a base teórica do estudo. O estado da arte, ou estado do conhecimento, tem caráter bibliográfico e visa mapear e discutir aspectos importantes e atuais da produção acadêmica em determinada área do conhecimento científico (Ferreira, 2002). Para fins desta pesquisa, o mapeamento do estado da arte abrangeu artigos científicos publicados nas principais bases de dados de periódicos nacionais e internacionais, sendo indexados os termos "gerenciamento da experiência do cliente", "canais de distribuição", "varejo", "integração de canais". Um dos objetivos dessa busca foi identificar o ineditismo da abordagem do gerenciamento de experiências do cliente, especificamente na integração das atividades on-line e off-line, no ambiente do varejo supermercadista.

A partir da indexação dos artigos de acordo com os termos apresentados, foi utilizada a análise de conteúdo como forma de tratamento. A análise de conteúdo obtém dados a partir da observação e análise do conteúdo propriamente dito, sendo que essa técnica de análise de dados também envolve a observação sistemática para identificar o conteúdo específico de informação e outras características das mensagens (Zikmund, 2006). Na visão de Cooper e Schindler (2003) a análise de conteúdo é uma técnica de pesquisa para descrição objetiva, sistemática e quantitativa do conteúdo de uma comunicação, utilizada para garantir a aplicação rigorosa de critérios de confiabilidade e validade, devido sua receptividade à computadorização. 
Dessa forma, foi realizada a análise de conteúdo com base nos elementos do modelo de Schmitt (2004). Estes elementos foram categorizados nos seguintes assuntos: características de ambientes experienciais do cliente; plataformas de experiências e pontos de contato; experiências desejadas para a marca; interfaces de interação com o cliente, e; processos de inovação contínua. Assim, as categorizações possibilitaram a seleção, exploração e análise das teorias identificadas no estado da arte.

\subsection{APRESENTAÇÃO DO NOVO CONSTRUCTO DE GEC}

Alguns conceitos apresentam um nível maior de abstração e subjetividade, não podendo ser transmitidos facilmente por meio de objetos, indivíduos ou situações. Assim, os constructos são os conjuntos de conceitos que auxiliam na explicação de abstrações de maior complexidade e subjetividade (Selltiz, Jahoda, Deutsch, \& Cook, 1967). Nas pesquisas de ciências sociais, um constructo é uma "imagem ou ideia inventada especificamente para uma determinada pesquisa e/ou criação de teoria". Dessa forma, como contribuição do presente ensaio, é pretendido apresentar um constructo específico ao ambiente varejista supermercadista, com a finalidade de implementar a gestão da experiência do cliente.

O modelo de Schmitt (2004) apresenta as etapas para estruturação de um programa completo de gerenciamento de experiências do cliente e serviu de base para o estudo. Os fundamentos teóricos propostos pelo autor demonstraram capacidade de ajustamento e serviram como suporte investigativo do ambiente supermercadista, possibilitando dessa forma, identificar características gerenciais das experiências dos clientes. Os atributos analisados a partir do modelo de Schmitt (2004) foram correlacionados a outra base teórica utilizada neste ensaio, na qual Terblanche (2018) contextualiza a experiência do cliente supermercadista e envolve o valor de mercadoria, o ambiente de loja, a interação com pessoal, a variedade de mercadorias e a emoção dos próprios clientes, demonstrando influência positiva e significativa nas satisfações dos mesmos.

Com base na revisão da literatura, é apresentado um constructo que envolve o gerenciamento das experiências dos clientes especificamente no segmento do varejo supermercadista. Esta concepção implementa o constructo apresentado por Terblanche (2018) e por isso é nomeada de constructo da experiência ampliada do cliente no supermercado, com uma dimensão adicionada: a integração das operações off-line e online. Essa nova dimensão congrega o acesso ou conhecimento dos clientes no canal físico do supermercado, integrando recursos, tecnologias e características do ambiente digital, tendo abrangência de operações dos canais sob a concepção omnichannel. Os principais objetivos, ao apresentar esse constructo, são: implementar as experiências do cliente no 
ponto de venda, influenciando e recebendo influências das demais dimensões do constructo e fornecer vantagem competitiva ao varejista supermercadista.

O novo constructo apresentado (Figura 3) amplia o escopo do gerenciamento das experiências dos clientes no ambiente supermercadista uma vez que explicita a necessidade de integração dos ambientes físico e virtual para proporcionar a ampliação das sensações experienciais. Essa integração pode apresentar diferentes níveis de abordagens, envolvendo maior ou menor implementação tecnológica, sendo adaptada às capacidades da organização varejista, tamanho do mercado, características regionais dos pontos de vendas e dos consumidores. Entretanto, independente do grau de inovações tecnológicas e valores monetários investidos no processo, as redes supermercadistas devem conceder atenção a essa nova dimensão de integração dos ambientes, sobretudo com o advento onipresente dos smartphones no cotidiano de seus clientes.

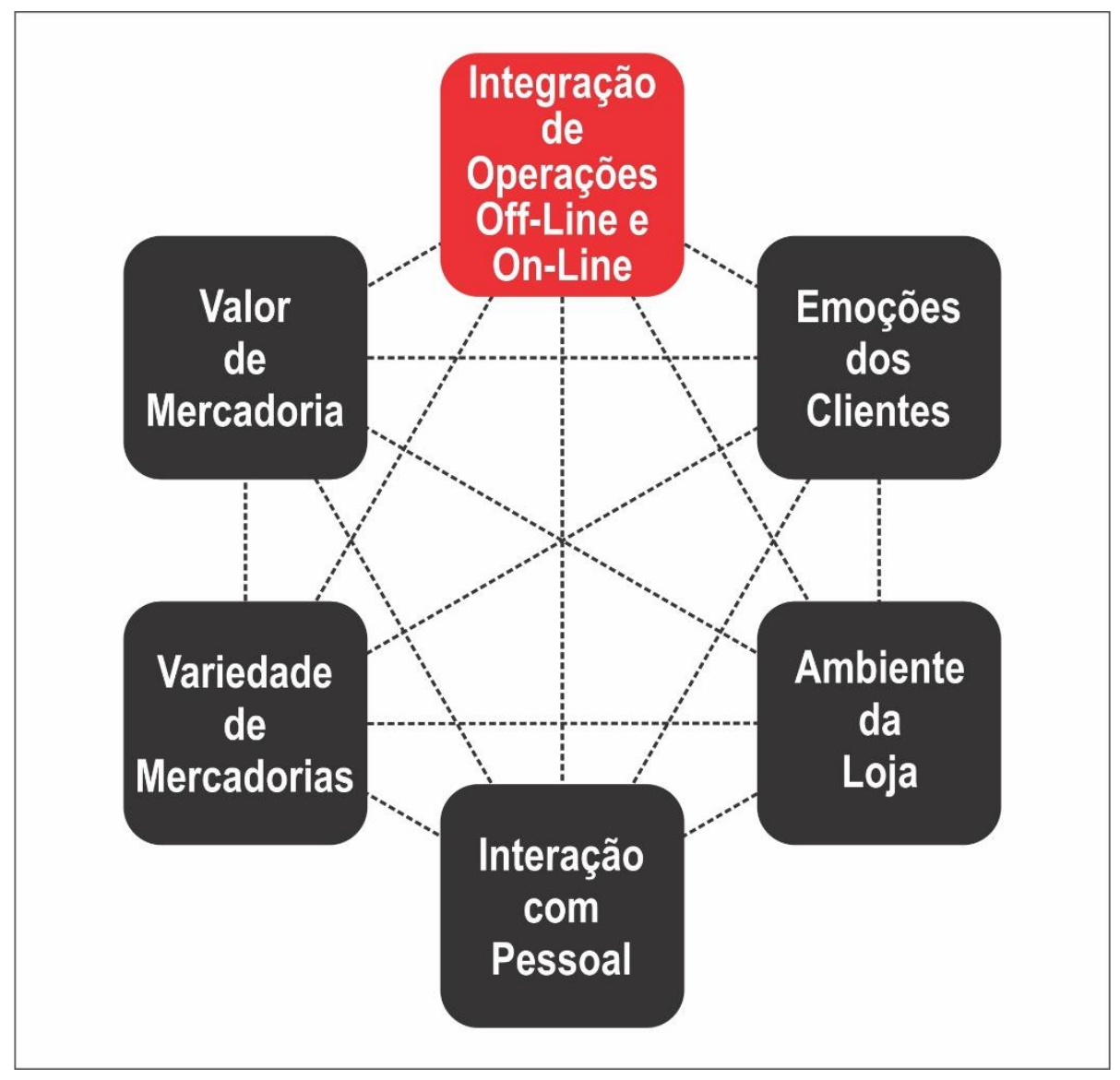

Figura 3: Constructo da experiência ampliada do cliente no supermercado Fonte: Elaborado pelo autor.

A dimensão adicionada ao constructo de experiência do cliente no supermercado é ainda mais relevante ao sofrer influências e influenciar nas demais dimensões, ao agregar valores intangíveis às mercadorias, melhorar a interação e dar destaque aos estímulos que 
compõem a atmosfera da loja, possibilitar mais intensidade no relacionamento com o pessoal de atendimento, proporcionar acesso a um maior número de variedade de mercadorias, bem como influenciar nas percepções e emoções dos clientes, seja de forma lúdica ou de forma utilitária.

Considerando a primeira etapa do modelo de projeto de gerenciamento de experiências, proposto por Schmitt (2004), abrange o ambiente experiencial do cliente. Nesse sentido, são percebidas as preocupações das organizações com o ambiente físico das lojas e seus inúmeros estímulos sensoriais e emocionais. Outros estímulos da atmosfera dos pontos de venda também desempenham importante papel no ato de proporcionar experiências adequadas, como o sortimento de produtos das lojas, nível de estoque, rastreabilidade, excelência de produtos e adaptações às necessidades dos clientes. Também deve haver uma preocupação constante em relação aos preços praticados nos dois ambientes - físico e virtual. Sendo que essa integração das operações das lojas físicas e virtuais precisam ser constantemente incentivadas de maneira prática para que isso aconteça. A prática envolve treinamentos, benefícios compartilhados, gerenciamento centralizado e acompanhamento diário. Caso contrário, a integração será apenas retórica.

As operações em um ambiente omnichannel fazem parte das definições estratégicas das organizações. Entretanto, é necessário que todos os colaboradores compreendam do que trata efetivamente esse termo, caso contrário pode transparecer apenas o uso de um modismo, integrante de planos da alta administração. Assim, neste cenário os inúmeros pontos de contato com os clientes no decorrer da sua jornada devem receber total atenção por parte das empresas interessadas em implementar essa estratégia de negócios. Especificamente no setor supermercadista, percebe-se que existem inúmeras possibilidades de pontos de atrito que devem ser trabalhadas constantemente nos aspectos operacionais do cotidiano das lojas. Assim, proporcionar experiências consistentes precisam do acompanhamento diário nos pontos de contato. As experiências estáticas devem receber total atenção para influenciar as experiências dinâmicas, considerando os inúmeros estímulos presentes no modelo holístico da experiência total do cliente.

As interações sociais entre os colaboradores e os clientes continuam sendo essenciais para o sucesso das operações nos diferentes canais. Mesmo com a utilização de inúmeras tecnologias, o fator humano desempenha um papel importante na experiência com o cliente supermercadista. Ainda que pareça evidente que o uso dos smartphones vai continuar mudando os comportamentos dos clientes, a complexidade em administrar essas interações envolve a também difícil gestão de pessoas e talentos internos para embasar todos os processos da empresa.

O ambiente supermercadista não é exclusivo para as orientações utilitárias. Diversas seções das lojas, sortimentos diferentes, momentos e ocasiões dos clientes também podem 
proporcionar orientações hedônicas. O supermercado se caracteriza como um ambiente misto de orientações de consumo, com inclinações utilitárias. Considerar operações omnichannel no varejo supermercadista ainda carece de práticas que integrem os canais de forma mais contundente, dadas as complexidades inerentes à aplicação do termo e de sua compreensão por todos os integrantes das organizações. Assim, integrar os ambientes off-line e on-line não significa simplesmente utilizar tecnologia no ambiente das lojas físicas. Essa integração pode envolver maior ou menor implementação tecnológica, sendo adaptada às capacidades da organização varejista, tamanho do mercado, características regionais dos pontos de vendas e dos consumidores.

\section{CONSIDERAÇÕES FINAIS}

A implementação de elementos e atividades que visam integrar os ambientes off-line e on-line apresenta novas maneiras e recursos na jornada do cliente. Ainda que exista um processo de adaptação do gerenciamento das experiências dos clientes por causa dos novos cenários, as empresas pioneiras e inovadoras na implementação do novo constructo devem alcançar vantagens competitivas no setor, alcançadas em relação a posicionamento perante o cliente, criação de novos hábitos, desenvolvimento da curiosidade dos clientes, facilidades no processo de compra ou ainda quanto ao movimento vanguardista no desempenho das operações logísticas do varejo.

Como implicações acadêmicas, este estudo fortalece conceitos e constructos da experiência dos clientes, explora as dimensões experienciais e estratégicas para o negócio de varejo, avança nas discussões sobre os movimentos comportamentais decorrentes das integrações entre operações dos diferentes canais disponibilizados aos clientes, evidencia a relevância dos pontos de contato entre empresas e clientes nas jornadas de compras e demonstra elementos para a construção de um relacionamento duradouro.

Ao atender o objetivo deste ensaio que é analisar como as dimensões da integração dos ambiente off-line e on-line estão presentes no gerenciamento da experiência do cliente, no segmento de varejo supermercadista, a principal contribuição teórica do estudo é a apresentação de um constructo ampliado das experiências dos clientes no ambiente do supermercado, que colabora para estudo do gerenciamento das experiências nesse contexto, assim como para as discussões sobre a estratégias de negócios varejistas. $O$ novo constructo indica um avanço nas discussões sobre o gerenciamento das experiências dos clientes no ambiente supermercadista pois envidencia a necessidade de integração dos ambientes físico e virtual para proporcionar a ampliação das sensações experienciais.

Além disso, as bases de construção teórica deste constructo e sua própria operacionalização indicam o desenvolvimento teórico que proporciona suporte ao contexto da pandemia COVID-19 e no futuro do varejo pós-pandemia. Com as mudanças de 
comportamentos dos consumidores, advindas de exigências da pandemia, os ambientes físico e virtual das redes varejistas devem aumentar sua sinergia e ampliam o desenvolvimento científico no sentido de tornar a dimensão "integração dos ambientes offline e on-line" um objeto relevante para estudos futuros.

Essa dimensão integrativa dos ambientes, apresentada no novo constructo, considera diferentes níveis de abordagens. Como apresentado anteriormente neste estudo, as abordagens envolvem maior ou menor implementação tecnológica, são adaptadas às capacidades da organização varejista, ao tamanho do mercado, às características regionais dos pontos de vendas e devem considerar os comportamentos e hábitos dos consumidores.

Outra ordenação teórica é a sistematização e a amplitude de aspectos do gerenciamento de varejo, considerando os componentes das atmosferas ambientais e abordagens experienciais. Assim, apesar das experiências dos clientes serem percepções subjetivas e particulares dos indivíduos, possuem elementos que devem ser gerenciados pela organização varejista. A base teórica de estudos sobre a experiência dos clientes evidencia que esta é formada por aspectos cognitivos, sensoriais, emocionais e sociais, com inúmeros estímulos antecedentes que compõem a experiência total de compra e que apresentam condições inerentes de serem administradas pela empresa. O novo constructo é apresentado como uma base teórica condizente ao gerenciamento dos estímulos que af etam os clientes, as operações dos processos no varejo, as atmosferas das lojas física e virtual do varejo, apresentando a efetiva integração desses ambientes e sua inter-relação com as demais dimensões do constructo de experiência.

Ao considerar suas dimensões e a integração ampliada dessas relações, o constructo também cria base teórica para evidenciar que o varejo deve agregar serviços on-line às atividades no ambiente físico para melhorar a experiência de consumo, uma vez que a integração dos canais físico e virtual pode proporcionar mudanças positivas nas percepções e nos comportamentos dos clientes, seja com orientações de compras hedônicas ou utilitárias.

Dessa forma, o novo constructo apresentado também tem objetivos que influenciam positivamente as ações gerenciais. Sua análise e efetiva aplicação no ambiente empresarial poderá, como descrito anteriormente, implementar as experiências do cliente no ponto de venda e fornecer vantagem competitiva ao varejista supermercadista.

A principal contribuição gerencial deste estudo reside no fato de que, apesar das experiências dos clientes serem percepções subjetivas e particulares dos indivíduos, possuem diversos aspectos que devem ser gerenciados pelo varejista. Como a experiência dos clientes é formada por aspectos cognitivos, sensoriais, emocionais e sociais, existem muitos estímulos antecedentes que compõem a experiência total de compra e que apresentam condições inerentes de serem administradas pela empresa. São fatores gerenciáveis os estímulos que afetam os clientes, as operações dos processos no varejo, 
as atmosferas das lojas física e virtual do varejo, assim como a integração desses ambientes. Dessa forma, o varejista deve ter conhecimento de que o gerenciamento das experiências dos clientes é uma de suas atribuições e possibilidades na busca do sucesso empresarial.

O varejo que efetivamente apresenta a proposta experiencial possibilita que o cliente tenha sensações positivas e se envolva com a marca da própria loja. Muitas vezes, os clientes participam ativamente e são co-criadores das experiências (Klein, Falk, Esch, \& Gloukhovtsev, 2016). Dessa forma, a utilização de estratégias e operações que estimulem lojas experienciais têm alterado a forma de gerenciar o varejo em si (Bäckström \& Johansson, 2006; Watson, Alexander, \& Salavati, 2018). Isso endossa e aproxima a realidade empresarial dos estudos originais de Mehrabian e Russell (1974), Holbrook e Hirschman (1982), Pine e Gilmore (1998) e Schmitt (2004) sobre as experiências dos clientes no ambiente das lojas. Assim, a partir da análise da nova dimensão proposta integração dos ambientes off-line e on-line - ao constructo da experiência ampliada do cliente, é apresentado subsídio relevante para a implementação do gerenciamento das experiências por parte dos varejos supermercadistas.

\section{REFERÊNCIAS}

Abbott, L. (1955). Quality and Competition: An Essay in Economic Theory. New York: Columbia University Press.

ABRAS - Associação Brasileira de Supermercados. (2019). Vendas dos supermercados cresceram 2,07\% em 2018. Recuperado 6 de fevereiro de 2019, de http://www.abras.com.br/clipping. php?area $=20 \&$ clipping $=67239$

Aguiar, E. C., \& Farias, S. A. de. (2014). Estímulos Sensoriais e seus Significados para o Consumidor: Investigando uma Atmosfera de Serviço Centrado na Experiência. Revista Brasileira de Marketing, 13(05), 65-77. https://doi.org/10.5585/remark.v13i5. 2494

Antéblian, B., Filser, M., \& Roederer, C. (2013). Consumption experience in retail environments: A literature review. Recherche et Applications en Marketing (English Edition), 28(3), 82-109. https://doi.org/10.1177/2051570713505471

Bäckström, K., \& Johansson, U. (2006). Creating and consuming experiences in retail store environments: Comparing retailer and consumer perspectives. Journal of Retailing and Consumer Services, 13(6), 417-430. https://doi.org/10.1016/j.jretconser.2006.02.005

Baker, J., Parasuraman, A., Grewal, D., \& Voss, G. B. (2002). The Influence of Multiple Store Environment Cues on Perceived Merchandise Value and Patronage Intentions. Journal of Marketing, 66(2), 120-141. https://doi.org/10.1509/jmkg.66.2.120.18470 
Balasubramanian, S., Raghunathan, R., \& Mahajan, V. (2005). Consumers in a multichannel environment: Product utility, process utility, and channel choice. Journal of Interactive Marketing, 19(2), 12-30. https://doi.org/10.1002/dir.20032

Beck, N., \& Rygl, D. (2015). Categorization of multiple channel retailing in Multi-, Cross-, and Omni-Channel Retailing for retailers and retailing. Journal of Retailing and Consumer Services, 27, 170-178. https://doi.org/10.1016/j.jretconser.2015.08.001

Bendoly, E., Blocher, J. D., Bretthauer, K. M., Krishnan, S., \& Venkataramanan, M. A. (2005). Online/in-store integration and customer retention. Journal of Service Research, 7(4), 313-327. https://doi.org/10.1177/1094670504273964

Bèzes, C. (2018). What kind of in-store smart retailing for an omnichannel real-life experience? Recherche et Applications en Marketing (English Edition), 01-22. https://doi.org/10.1177/2051570718808132

Bolton, R. N., McColl-Kennedy, J. R., Cheung, L., Gallan, A., Orsingher, C., Witell, L., \& Zaki, M. (2018). Customer experience challenges: bringing together digital, physical and social realms. Journal of Service Management, 29(5), 776-808. https://doi.org/10.1108/JOSM-04-2018-0113

Bonnin, G., \& Goudey, A. (2012). The kinetic quality of store design: An Exploration of its influence on shopping experience. Journal of Retailing and Consumer Services, 19(6), 637-643. https://doi.org/10.1016/j.jretconser.2012.08.006

Brito, E. P. Z., Vieira, V. A., \& Espartel, L. B. (2011). A Pesquisa na Área do Varejo: reflexões e provocações. RAE - Revista de Administração de Empresas, 51(6), 522-527.

Campo, K., \& Breugelmans, E. (2015). Buying Groceries in Brick and Click Stores: Category Allocation Decisions and the Moderating Effect of Online Buying Experience. Journal of Interactive Marketing, 31, 63-78. https://doi.org/10.1016/j.intmar.2015.04.001

Cook, G. (2014). Customer experience in the omni-channel world and the challenges and opportunities this presents. Journal of Direct, Data and Digital Marketing Practice, 15(4), 262-266. https://doi.org/10.1057/dddmp. 2014.16

Cooper, D. R., \& Schindler, P. S. (2003). Métodos de Pesquisa em Administração (7a edição). Porto Alegre: Bookman.

D'Ippolito, B., \& Timpano, F. (2016). The Role of Non-Technological Innovations in Services: The Case of Food Retailing. Creativity and Innovation Management, 25(1), 7389. https://doi.org/10.1111/caim. 12156

Dziewanowska, K. (2015). Comparison of Dimensions of Online and Offline Shopping Experiences. In Annual Paris Business Research Conference. Paris.

Errajaa, K., Legohérel, P., \& Daucé, B. (2018). Immersion and emotional reactions to the ambiance of a multiservice space: The role of perceived congruence between odor and brand image. Journal of Retailing and Consumer Services, 40(August 2017), 100-108. https://doi.org/10.1016/j.jretconser.2017.08.016

Ferreira, N. S. de A. (2002). As pesquisas denominadas "estado da arte". Educação \& Sociedade, 23(79), 257-272. https://doi.org/10.1590/S0101-73302002000300013 
Flavián, C., Gurrea, R., \& Orús, C. (2016). Choice confidence in the webrooming purchase process: The impact of online positive reviews and the motivation to touch. Journal of Consumer Behaviour, 15, 459-476.

Følstad, A., \& Kvale, K. (2018). Customer journeys: a systematic literature review. Journal of Service Theory and Practice (Vol. 28). https://doi.org/10.1108/JSTP-11-20140261

Gentile, C., Spiller, N., \& Noci, G. (2007). How to Sustain the Customer Experience: An Overview of Experience Components that Co-create Value With the Customer. European Management Journal, 25(5), 395-410. https://doi.org/10.1016/j.emj.2007.08.005

Grewal, D., Levy, M., \& Kumar, V. (2009). Customer Experience Management in Retailing: An Organizing Framework. Journal of Retailing, 85(1), 1-14. https://doi.org/10.1016/j.jretai.2009.01.001

Grewal, D., Roggeveen, A. L., \& Nordfält, J. (2017). The Future of Retailing. Journal of Retailing, 93(1), 1-6. https://doi.org/10.1016/j.jretai.2016.12.008

Hand, L., Parker, B., Ortis, I., \& Holmes, C. (2009). 2009 Top Ten Predictions for the Retail Industry. (Relatório nº GRI216086, 05.jan.2009). IDC Retail Insights.

Helm, S., Kim, S. H., \& Van Riper, S. (2018). Navigating the 'retail apocalypse': A framework of consumer evaluations of the new retail landscape. Journal of Retailing and Consumer Services. https://doi.org/10.1016/j.jretconser.2018.09.015

Herhausen, D., Binder, J., Schoegel, M., \& Herrmann, A. (2015). Integrating Bricks with Clicks: Retailer-Level and Channel-Level Outcomes of Online-Offline Channel Integration. Journal of Retailing, 91(2), 309-325. https://doi.org/10.1016/j.jretai.2014.12.009

Hernández-Ortega, B., \& Franco, J. L. (2018). Developing a new conceptual framework for experience and value creation. Service Business. https://doi.org/10.1007/s11628-018-0379-4

Hilken, T., Heller, J., Chylinski, M., Keeling, D. I., Mahr, D., \& de Ruyter, K. (2018). Making omnichannel an augmented reality: the current and future state of the art. Journal of Research in Interactive Marketing, 12(4), 509-523. https://doi.org/10.1108/JRIM-012018-0023

Hoffman, K. D., \& Turley, L. W. (2002). Atmospherics, service encounters and consumer decision making: an integrative perspective. Journal of Marketing Theory and Practice, 10(3), 33-47. Recuperado de https://www.jstor.org/stable/41304272

Holbrook, M. B., \& Hirschman, E. C. (1982). The Experiential Aspects of Consumption: Consumer Fantasies, Feelings, and Fun. Journal of Consumer Research, 9(2), 132. https://doi.org/10.1086/208906

Homburg, C., Jozić, D., \& Kuehnl, C. (2017). Customer experience management: toward implementing an evolving marketing concept. Journal of the Academy of Marketing Science, 45(3), 377-401. https://doi.org/10.1007/s11747-015-0460-7

Höpner, A., Ganzer, P. P., Chais, C., \& Olea, P. M. (2015). Experiência do Consumidor no Varejo: Um Estudo Bibliométrico. Revista Brasileira de Marketing, 14(04), 513-528. https://doi.org/10.5585/remark.v14i4. 2977 
Hwangbo, H., Kim, Y. S., \& Cha, K. J. (2017). Use of the Smart Store for Persuasive Marketing and Immersive Customer Experiences: A Case Study of Korean Apparel Enterprise. Mobile Information Systems, 2017. https://doi.org/10.1155/2017/4738340

Ieva, M., \& Ziliani, C. (2018a). Mapping touchpoint exposure in retailing. International Journal of Retail \& Distribution Management, 46(3), 304-322. https://doi.org/10.1108/IJRDM-04-2017-0097

Jaziri, D. (2019). The advent of customer experiential knowledge management approach (CEKM): The integration of offline \& online experiential knowledge. Journal of Business Research, 94, 241-256. https://doi.org/10.1016/j.jbusres.2018.05.029

Kang, J. Y. M. (2018). Showrooming, Webrooming, and User-Generated Content Creation in the Omnichannel Era. Journal of Internet Commerce, 17(2), 145-169. https://doi.org/10.1080/15332861.2018.1433907

Kazancoglu, I., \& Aydin, H. (2018). An investigation of consumers' purchase intentions towards omni-channel shopping. International Journal of Retail \& Distribution Management, 46(10), 959-976. https://doi.org/10.1108/IJRDM-04-2018-0074

Kim, S., Ham, S., Moon, H., Chua, B. L., \& Han, H. (2018). Experience, brand prestige, perceived value (functional, hedonic, social, and financial), and loyalty among GROCERANT customers. International Journal of Hospitality Management, 0-1. https://doi.org/10.1016/j.ijhm.2018.06.026

Klein, J. F., Falk, T., Esch, F. R., \& Gloukhovtsev, A. (2016). Linking pop-up brand stores to brand experience and word of mouth: The case of luxury retail. Journal of Business Research, 69(12), 5761-5767. https://doi.org/10.1016/j.jbusres.2016.04.172

Koetz, C. (2018). Managing the customer experience: a beauty retailer deploys all tactics. Journal of Business Strategy, JBS-09-2017-0139. https://doi.org/10.1108/JBS-092017-0139

Kotler, P. (1973). Atmospherics as a Marketing Tool. Journal of Retailing, 49(4), 4864. https://doi.org/10.1016/j.obhdp.2011.03.002

Kumar, V., \& Karande, K. (2000). The effect of retail store environment on retailer performance. Journal of Business Research, 49(2), 167-181. https://doi.org/10.1016/S0148-2963(99)00005-3

Lam, S. Y. (2001). The Effects of Store Environment on Shopping Behaviors: A Critical Review. Advances in Consumer Research, 28(1), 190-197. https://doi.org/Article

Larke, R., Kilgour, M., \& O'Connor, H. (2018). Build touchpoints and they will come: transitioning to omnichannel retailing. International Journal of Physical Distribution and Logistics Management, 48(4), 465-483. https://doi.org/10.1108/IJPD LM-09-2016-0276

Lazaris, C., \& Vrechopoulos, A. (2014). From Multichannel to "Omnichannel" Retailing: Review of the Literature and Calls for Research. In 2nd International Conference on Contemporary Marketing Issues. Athens, Greece: ICCMI. https://doi.org/10.13140/2.1.1802.4967

Lemon, K. N., \& Verhoef, P. C. (2016). Understanding Customer Experience Throughout the Customer Journey. Journal of Marketing, 80(6), 69-96. https://doi.org/10.1509/jm.15.0420 

Hill/Irwin.

Levy, M., \& Weitz, B. A. (2012). Retailing Management (8th ed). New York: McGraw-

Martineau, P. (1958). The Personality of the Retail Store. Harvard Business Review, $36(1), 47-55$.

Mehrabian, A., \& Russell, J. A. (1974). An Approach to Environmental Psychology. Cambridge: MIT Press.

Micheaux, A., \& Bosio, B. (2018). Customer Journey Mapping as a New Way to Teach Data-Driven Marketing as a Service. Journal of Marketing Education, 01-14. https://doi.org/10.1177/0273475318812551

Mohan, G., Sivakumaran, B., \& Sharma, P. (2013). Impact of store environment on impulse buying behavior. European Journal of Marketing, 47(10), 1711-1732. https://doi.org/10.1108/EJM-03-2011-0110

Mosquera, A., Juaneda-Ayensa, E., Olarte-Pascual, C., \& Sierra-Murillo, Y. (2018). The role of technology in an omnichannel physical store: assessing the moderating effect of gender. Spanish Journal of Marketing - ESIC, In press. https://doi.org/10.1108/SJ ME03-2018-008

Neslin, S. A., Grewal, D., Leghorn, R., Shankar, V., Teerling, M. L., Thomas, J. S., \& Verhoef, P. C. (2006). Challenges and opportunities in multichannel customer management. Journal of Service Research, 9(2), 95-112. https://doi.org/10.1177/1094670506293559

Neslin, S. A., \& Shankar, V. (2009). Key Issues in Multichannel Customer Management: Current Knowledge and Future Directions. Journal of Interactive Marketing, 23(1), 70-81. https://doi.org/10.1016/j.intmar.2008.10.005

Otieno, R., Harrow, C., \& Lea-Greenwood, G. (2005). The unhappy shopper, a retail experience: exploring fashion, fit and affordability. International Journal of Retail \& Distribution Management, 33(4), 298-309. https://doi.org/10.1108/09590550510593220

Pandey, S., \& Chawla, D. (2018). Online customer experience (OCE) in clothing eretail: Exploring OCE dimensions and their impact on satisfaction and loyalty - Does gender matter? International Journal of Retail \& Distribution Management, 46(3), 323-346. https://doi.org/https://doi.org/10.1108/IJRDM-01-2017-0005

Pantano, E. (2010). New technologies and retailing: Trends and directions. Journal
of Retailing and Consumer Services, 17(3), 171-172. https://doi.org/10.1016/j.jretconser.2010.03.004

Pantano, E., \& Timmermans, H. (2014). What is Smart for Retailing? Procedia Environmental Sciences, 22, 101-107. https://doi.org/10.1016/j.proenv.2014.11.010

Park, C. W., Iyer, E. S., \& Smith, D. C. (1989). The Effects of Situational Factors on In-Store Grocery Shopping Behavior: The Role of Store Environment and Time Available for Shopping. Journal of Consumer Research, 15(4), 422. https://doi.org/10.1086/209182

Picot-Coupey, K., Huré, E., \& Piveteau, L. (2016). Channel design to enrich customers' shopping experiences. International Journal of Retail \& Distribution Management, 44(3), 336-368. https://doi.org/10.1108/IJRDM-04-2015-0056 
Pine, B. J., \& Gilmore, J. H. (2013). The experience economy: past, present and future. In J. Sundbo \& F. Sørensen (Orgs.), Handbook on the Experience Economy (p. 2144). Cheltenham (UK): Edward Elgar Publishing Ltd. https://doi.org/10.4337/9781781004227.00007

Pine, B. J. I., \& Gilmore, J. H. (2011). The Experience Economy: Updated Edition. Boston: Harvard Business Press.

Piotrowicz, W., \& Cuthbertson, R. (2014). Introduction to the Special Issue Information Technology in Retail: Toward Omnichannel Retailing. International Journal of Electronic Commerce, 18(4), 5-16. https://doi.org/10.2753/JEC1086-4415180400

Poncin, I., \& Ben Mimoun, M. S. (2014). The impact of "e-atmospherics" on physical stores. Journal of Retailing and Consumer Services, 21(5), 851-859. https://doi.org/10.1016/j.jretconser.2014.02.013

Puccinelli, N. M., Goodstein, R. C., Grewal, D., Price, R., Raghubir, P., \& Stewart, D. (2009). Customer Experience Management in Retailing: Understanding the Buying Process. Journal of Retailing, 85(1), 15-30. https://doi.org/10.1016/j.jretai.2008.11.003

Rosenbaum, M. S., Otalora, M. L., \& Ramírez, G. C. (2017). How to create a realistic customer journey map. Business Horizons, 60(1), 143-150. https://doi.org/10.1016/j.bushor.2016.09.010

Sachdeva, I., \& Goel, S. (2015). Retail store environment and customer experience: a paradigm. Journal of Fashion Marketing and Management, 19(3), 290-298. https://doi.org/10.1108/JFMM-03-2015-0021

SBVC - Sociedade Brasileira de Varejo e Consumo. (2018). Ranking: um estudo completo do varejo. Revista Ranking: um estudo completo do varejo - 300 maiores empresas, 156.

Schmitt, B. H. (2004). Gestão da experiência do cliente: uma revolução no relacionamento com os consumidores. Porto Alegre: Bookman.

Selltiz, C., Jahoda, M., Deutsch, M., \& Cook, S. W. (1967). Métodos de Pesquisa nas Relações Sociais. São Paulo: Editora Herder.

Shankar, V. (2018). How Artificial Intelligence (AI) Is Reshaping Retailing. Journal of Retailing, 94(4), vi-xi. https://doi.org/10.1016/S0022-4359(18)30076-9

Shen, X. L., Li, Y. J., Sun, Y., \& Wang, N. (2018). Channel integration quality, perceived fluency and omnichannel service usage: The moderating roles of internal and external usage experience. Decision Support Systems, 109, 61-73. https://doi.org/10.1016/j.dss.2018.01.006

Sirohi, N., McLaughlin, E. W., \& Wittink, D. R. (1998). A model of consumer perceptions and store loyalty intentions for a supermarket retailer. Journal of Retailing, 74(2), 223-245. https://doi.org/10.1016/S0022-4359(99)80094-3

Terblanche, N. S. (2018). Revisiting the supermarket in-store customer shopping experience. Journal of Retailing and Consumer Services, 40(June 2017), 48-59. https://doi.org/10.1016/j.jretconser.2017.09.004

Turley, L. W., \& Milliman, R. E. (2000). Atmospheric Effects on Shopping Behavior: A Review of the Experimental Evidence. Journal of Business Research, 49, 193-211. https://doi.org/10.1016/S0148-2963(99)00010-7 
Verhoef, P. C., Kannan, P. K., \& Inman, J. J. (2015). From Multi-Channel Retailing to Omni-Channel Retailing. Introduction to the Special Issue on Multi-Channel Retailing. Journal of Retailing, 91(2), 174-181. https://doi.org/10.1016/j.jretai.2015.02.005

Verhoef, P. C., Lemon, K. N., Parasuraman, A., Roggeveen, A., Tsiros, M., \& Schlesinger, L. A. (2009). Customer Experience Creation: Determinants, Dynamics and Management Strategies. Journal of Retailing, 85(1), 31-41. https://doi.org/10.1016/j.jretai.2008.11.001

Watson, A., Alexander, B., \& Salavati, L. (2018). The impact of experiential augmented reality applications on fashion purchase intention. International Journal of Retail and Distribution Management. https://doi.org/10.1108/IJRDM-06-2017-0117

Zikmund, W. G. (2006). Princípios da Pesquisa de Marketing. São Paulo: Pioneira Thomson Learning.

Zomerdijk, L. G., \& Voss, C. A. (2010). Service design for experience-centric services. Journal of Service Research, 13(1), 67-82. https://doi.org/10.1177/1094670509351960 